\title{
Freedom and quality of life
}

There is a double belief that causes health authorities to hold back from vigorously promoting healthy behaviours. The first is linked to the idea that there is a trade off between the quantity and the quality of life. Why increase the individual length of life if it is at the price of the quality of the years lived. But what do we mean by the quality of the years lived? Happiness or well being? This approach is considered too wide by the important literature devoted to this question in the field of health and social science. Experts in this field prefer to limit quality of life to what is conventionally called Health related Quality of Life (HRQoL). The key elements are, then, pain and self perceived symptoms, functional status and disability and perceived health.

In this issue, Wilma Nusselder and her colleagues ${ }^{1}$ show that smoking elimination would have a proportionally more important effect in terms of decrease in disability than in terms of decrease in mortality. Smoking elimination would increase disability free life expectancy more than total life expectancy, thus leading to an absolute reduction of the number of years lived with disability. This result, which shows that smoking is a cause of a great number of years lived with disability, is the best answer we can give to those who think that smoking would save money by killing smokers before they get too old and disabled. This work adds to the work of Vita and colleagues ${ }^{2}$ and to the work of Ferrucci and colleagues ${ }^{3}$ demonstrating that healthy behaviours do not decrease the quality of the years lived if this latter is assessed through functional status and disability. The study conducted by Vita et al suggests that people with the best health habits and the lowest risks (nonsmoking, regular physical activity, normal body mass index value) not only live longer but also postpone the onset age of disability and benefit from a compression of the number of years lived with disability over a shorter period of time at the end of life. ${ }^{2}$ Ferrucci et al showed that people with the best risk profile (non-smokers with high physical activity) have a much higher disability free life expectancy than those with a poor risk profile. ${ }^{3}$ In this study, good risk profiles correspond both to the longest disability free life expectancy and the longest life expectancy with disability. None of these three studies suggests that there is a trade off between quantity and quality of life, but rather, at least for two of them, that there is a possible compression of disability, with quantity and quality going hand in hand. Other authors have found that there is still a relation between smoking and poor self rated health when factors like socioeconomic status, educational level, obesity and physical inactivity are controlled. ${ }^{4}$ The Duke health profile, providing information about perceived health and quality of life, shows that young French smokers (12-19 year olds) have less good physical and mental health scores than non-smokers. ${ }^{5}$ Whatever the indicator of HRQoL, functional status, disability and self perceived health, there is a negative relation between smoking and quality of life.

The second belief is linked to the idea that notions or concepts of "healthy behaviours" or "successful aging" could be too normative and destructive to individual freedom. Promotion of healthy behaviours could become the promotion of a correct way to live and to age. A very large majority of French young people $(82.4 \%)$ think that smokers are dependent on tobacco in the same way as on another addictive drug. They are also almost unanimous $(91.5 \%)$ in saying that smokers are responsible for their own health problems. ${ }^{5}$ Could adults and health authorities be as responsible as young people and tackle tobacco smoking with a cold determination. New studies are needed to better understand the needs met by smoking and to develop new strategies to reduce tobacco consumption, of which the smokers are the first victims.

J M ROBINE

INSERM, Demographie et Sante, Val d'Aurelle-Parc Euromedicine, 34298 Montpellier cedex 5, France (robine@valdorel.fnclcc.fr)

1 Nusselder WJ, Looman CWN, Marang-van de Mheen PJ, et al. Smoking and the compression of morbidity. $\mathcal{F}$ Epidemiol Community Health 2000;54:566-74.

2 Vita AJ, Terry RB, Hubert HB, et al. Aging, health risk, and cumulative disability. N Engl f Med 1998;338:1035-41.

3 Ferrucci L, Izmirliam G, Leveille SG, et al. Smoking, physical activity and active life expectancy. Am f Epidemiology 1999;149:645-53.

4 Malmström M, Sunquist J, Johansson SE. Neighborhood environment and self-reported health status: a multilevel analysis. Am J Public Health 1999; 89:1181-6.

5 Baudier F, Velter A. Tabac. In: Baromètre santé jeunes 97/98. [English summary]. Paris: Comité Français d'Education pour la Santé, 1999:15979 . 